\title{
A Fair Queuing Technique for Efficient Content Delivery Over 3G and 4 G Networks in Varying Load Condition
}

\author{
B.K Mishra \\ Principal, Thakur College of \\ Engineering and Technology \\ Thakur Village,Kandivali (East) \\ Mumbai-400101
}

\author{
S.K Singh \\ Research Scholar-Mukesh Patel \\ School of Technology Management \\ and Engineering \\ NMIMS University, Santacruz \\ Mumbai-400056
}

\author{
Ruchi Shah \\ PG Student -Thakur College of \\ Science and Commerce, \\ Thakur Village, Kandivali (East) \\ Mumbai -400101
}

\begin{abstract}
The challenges of new communication architecture are to offer better quality of service (QoS) in internet Network. A large diversity of services based on packet switching in $3 G$ network and beyond 3G leads dramatic changes in the characteristics and parameter of data traffic. Deployment of application server and resource server has been proposed to support both high data rates and quality of service (QoS) for Next Generation Network (NGN).One important generalization of the Next Generation Network is, it's a queue of network. It is expected that traffic in NGN will undergo both quantitative and qualitative changes. Such networks can model problems of contention that arise when a set of resources is shared. With the rapid transformation of the Internet into a commercial infrastructure, demands for service quality have rapidly developed. In this paper, few components of NGN reference architecture have been taken and system is evaluated in terms of queuing network. This paper gives a comparative analysis of three queuing systems FIFO, PQ and WFQ. Packet end to end delay, packet delay variation and traffic dropped are evaluated through simulation. Results have been evaluated for a light load intermediate load and heavy load condition for constant traffic distribution. Results have been also evaluated for variable bandwidth condition. Result shows WFQ has better quality comparing with other techniques in a voice based services where as PQ a technique is better in Video based services. Simulation is done using OPNET.
\end{abstract}

Keywords- QoS-Quality of service; NGN-Next Generation Network; FIFO- First-in-first-out; PQ- Priority queuing; WFQ- WeightedFair queuing; VoIP-Voice over Internet Protocol.

\section{INTRODUCTION}

It is essential to understand and take a deep look in to the future, for a view of what a network may look like and explore how a service or group of services may fit together to form a useful example of where next generation network will take us.

To offer better quality of service in a network a lot of parameter should be considered such as bandwidth, latency, delay, jitter and packet loss etc. NGN's architecture is based on decoupling transport layer and service layer. Basically, that means that whenever a provider wants to enable a new service they can do it straight upon defining it at the service layer without considering it the transport layer. Fig.-1 shows reference architecture of NGN model. Required components of NGN have been extensively discussed in past [1].

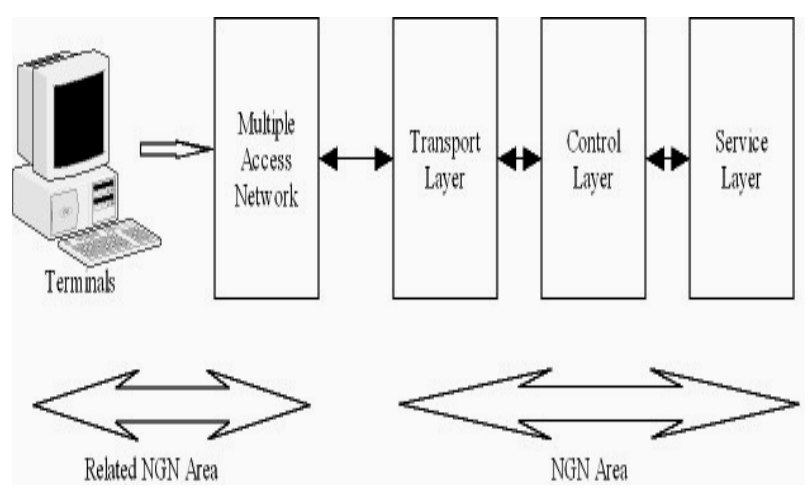

Figure 1. Reference Architecture Diagram of NGN Model

\section{METHODOLOGY AND REQUIREMENTS}

In next generation proposed architecture, these are following set of requirements.

- Drivers and basic requirements.

- NGN QoS standardization.

- Resource and admission control functions.

In order to meet some of the requirements listed for Next generation Network, some proposal has been discussed in past [2]. Voice and video based QoS is determined by many factors and the most important parameters are packet end-to-end delay, packet delay variations or jitter and packet drop. ITU-T Recommendation G.114 recommends the following limits for one-way end-to-end transmission time [3].

- 0 to $150 \mathrm{~ms}$ : Acceptable for most user applications.

- 150 to 400 ms: Acceptable provided that Administrations are aware of the transmission time impact on the transmission quality of user applications.

- Above 400 ms: Unacceptable for general network planning purpose. However, it is recognized that in some exceptional cases this limit will be exceeded.

\section{THE ANALYTICAL DECOMPOSITION OF NGN REFERENCE MODEL WITH OPEN QUEUING NETWORK}

In the generic model a node or a service center represent each resource. Thus in a model for computer system performance analysis we may have service center for the servers, a service center for each I/O channel [4]. 
In order to provide a requested QoS, the nodes of a network must perform session initiation phase, reservation setup, admission control, policy control, packet scheduling, and packet classification functions.

A service center may have one or more server associated with it. If a job requesting service finds all the server at a service center busy, it will join the queue associated with the center and a later point in time when a server becomes idle a job from the queue will be selected for service according to some scheduling discipline. After completion of service at one service center the job may move to another service center for further service, reenter the same service center or leave the system [5].

Consider a two stage tandem network. The system consists of application server and resource server with respective service rate $\mu_{0} \& \mu_{1}$. Observe that application server has a Poisson arrival source of rate $\lambda$ and exponentially distributed.

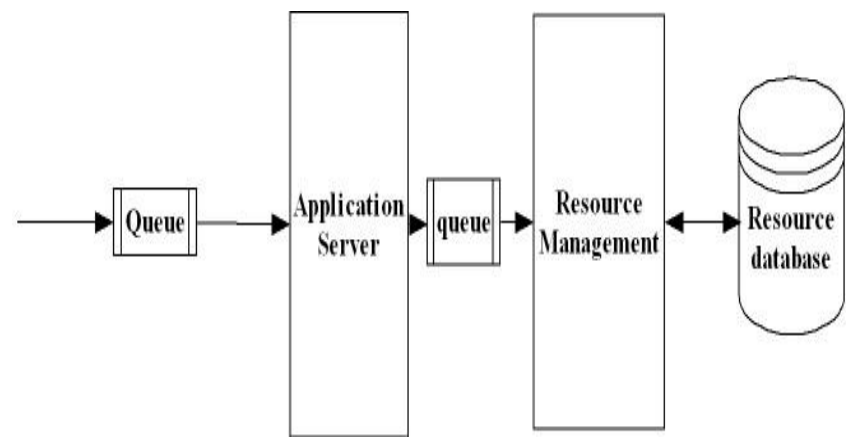

Figure 2. A two stage open queuing network of NGN

This system can be modeled as a stochastic process whose states are specified by pairs $\left(k_{0}, k_{1}\right)$.

$$
\begin{aligned}
& k_{0} \geq 0 \\
& k_{1} \geq 0
\end{aligned}
$$

Where $k_{i}(\mathrm{i}=0,1)$ is the no. of jobs completion of the service at one of the two server. The changes of the two servers occur on a completion of service at one of the two servers or an external arrival. Since all interevent times are exponentially distributed, it follows that the stochastic process is a homogeneous continuous time Markov chain [6].

Let $\mathrm{p}\left(k_{0}, k_{1}\right)$ is the joint probability of $k_{0}$ jobs at application server and $k_{1}$ Jobs at resource server in the steady state. Equating the rates of flow into and out of the state, we obtain the following balance equations [7].

$$
\begin{aligned}
& \left(\mu_{0}+\mu_{1}+\lambda\right) p\left(k_{0}, k_{1}\right)=\mu_{0} p\left(k_{0}+1, k_{1}-1\right)+ \\
& \mu_{1} p\left(k_{0}, k_{1}+1\right)+\lambda p\left(k_{0}-1, k_{1}\right)--(1)
\end{aligned}
$$

For the boundary state we have

$$
\begin{gathered}
\left(\mu_{0}+\lambda\right) p\left(k_{0}, 0\right)=\mu_{1} p\left(k_{0}, 1\right)+\lambda p\left(k_{0}-1\right) \\
\text { Where } k_{0}>0
\end{gathered}
$$

$$
\begin{gathered}
\left(\mu_{1}+\lambda\right) p\left(0, k_{1)}=\mu_{0} p\left(1-k_{1}-1\right)+\mu_{1} p\left(0, k_{1}+1\right)\right. \\
\text { Where k1>0 } \\
\lambda \cdot p(0,0)=\mu_{1} \cdot p(0,1)----(2)
\end{gathered}
$$

The normalization is provided by

$$
\sum_{k 0 \geq 0} \sum_{k 1 \geq 0} p\left(k_{0} k_{1}\right)=1
$$

The Solution of the preceding balance equation is

$$
\text { Where } \rho_{0}=\lambda / \mu_{0} \text { and } \rho_{1}=\lambda / \mu_{1} \text {----- (3) }
$$

The equation shows a stability condition of the network as condition for stability of the system is that both $\rho_{0} \& \rho_{1}$ are less than unity. Equation (3) is a product form solution to M/M/1 queue. Many efficient algorithms for calculating performance measure for closed queuing network have been developed and discussed in past [8] [9] [10].

\section{VARIOUS QUEUING TECHNIQUES}

There are number of elementary queuing models. Attention is paid to methods for the analysis of these models, and also to applications of queuing models on $3 \mathrm{G}$ and $4 \mathrm{G}$ network.

Various queuing disciplines can be used to control which packets get transmitted and which packets which packets get dropped. The queuing disciplines are:

- First-in-first-out (FIFO) queuing.

- Priority queuing (PQ)

- Weighted-Fair queuing. (WFQ)

FIFO is an acronym for First in First Out. This expression describes the principle of a queue or first-come first serve behavior: what comes in first is handled first, what comes in next waits until the first is finished etc. Thus it is analogous to the behavior of persons "standing in a line" or "Queue" where the persons leave the queue in the order they arrive. First In First out (FIFO) is the most basic queuing discipline. In FIFO queuing all packets are treated equally by placing them into a single queue, then servicing them in the same order they were placed in the queue. FIFO queuing is also referred to as First Come First Serve (FCFS) queuing [11]. Although a single FIFO queue seems to provide no QoS features at all, it actually does affect drop, delay, and jitter. Because there is only one queue, the router need not classify traffic to place it into different queues and router need not worry about how to decide from which queue it should take the next packet - there is only one choice. Due to this single queue uses FIFO logic, the router need not reorder the packets inside the queue. With a longer queue, however, the average delay increases, because packets may be enqueued behind a larger number of other packets. In most cases when the average delay increases, the average jitter increases as well.

Priority Queuing assigns multiple queues to a network interface with each queue being given a priority level. A queue with higher priority is processed earlier than a queue with lower priority. Priority Queuing has four preconfigured queues, high medium, normal and low priority queue. Queues 
are serviced in strict order of queue priority, so the high queue always is serviced first, then the next-lower priority and so on. If a lower-priority queue is being serviced and a packet enters a higher queue, that queue is serviced immediately. This mechanism is good for important traffic, but can lead to queue starvation. If packets arrive in the high queue then priority queuing drops everything its doing in order to transmit those packets, and the packets in other queue is again empty. When a packet is sent out an interface, the priority queues on that interface are scanned for packets in descending order for priority. The high priority queues is scanned first, then the medium priority queue and then so on. The packet at the head of the highest queue is chosen for transmission. This procedure is repeated every time when a packet is to be sent. The maximum length of a queue is defined by the length limit. When a queue is longer the limit packets are dropped [12].

The idea of the fair queuing (FQ) discipline is to maintain a separate queue for each flow currently being handled by the router. The router then services these queues in a round robin manner. WFQ allows a weight to be assigned to each flow (queue). This weight effectively controls the percentage of the link's bandwidth each flow will get. WFQ is a generalization of fair queuing (FQ) [13] [14] [15]. Both in WFQ and FQ, each data flow has a separate FIFO queue.

\section{NETWORK DESIGN AND CONFIGURATION}

The following network design has been taken into consideration to evaluate network performance on various queuing network. At the first step single traffic is used for each of the functions such as Ftp, Video Conferencing and VoIP which is shown in Fig 3. Fig 4 and Fig 5 shows intermediate and heavy traffic load condition and it uses three and four routers. For $3 \mathrm{G}$ and $4 \mathrm{G}$ requirement the basic architecture can be modified with reference of bandwidth. The network model has been configured for constant traffic condition result has been explored for voice and video application using FIFO, PQ, and WFQ queuing discipline.

Performance based on queuing network has been discussed in past using various queuing policy but failed to achieve wide acceptance due to various complexity [16] [17].

The below configurations applied in the Opnet Modeler and simulated to get results.

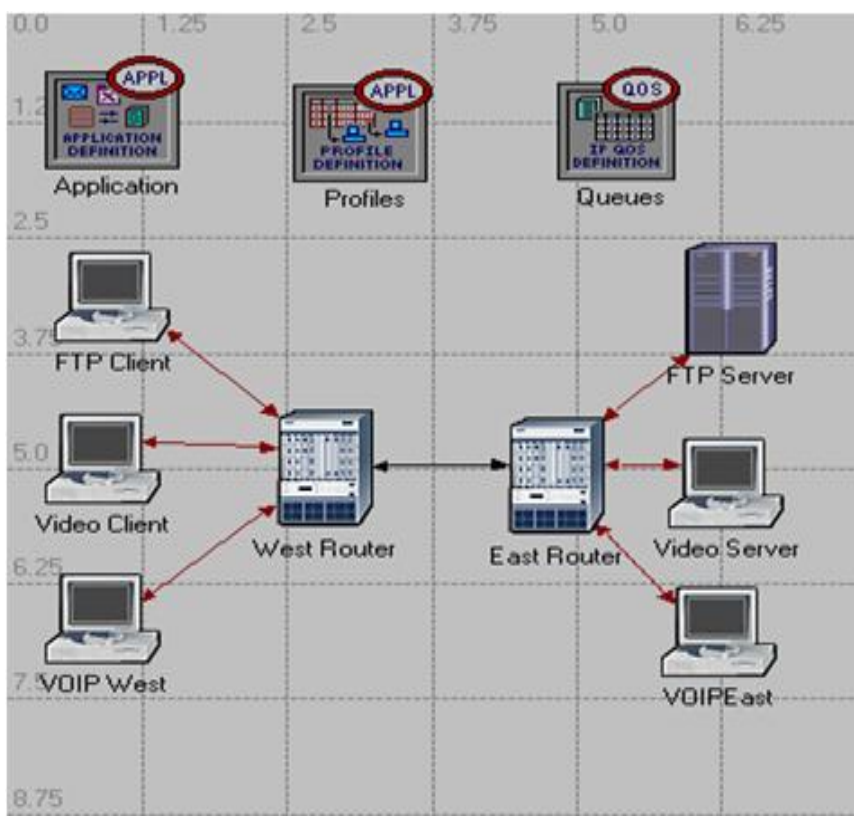

Figure 3. Network architecture for FIFO, PQ and WFQ for light load.

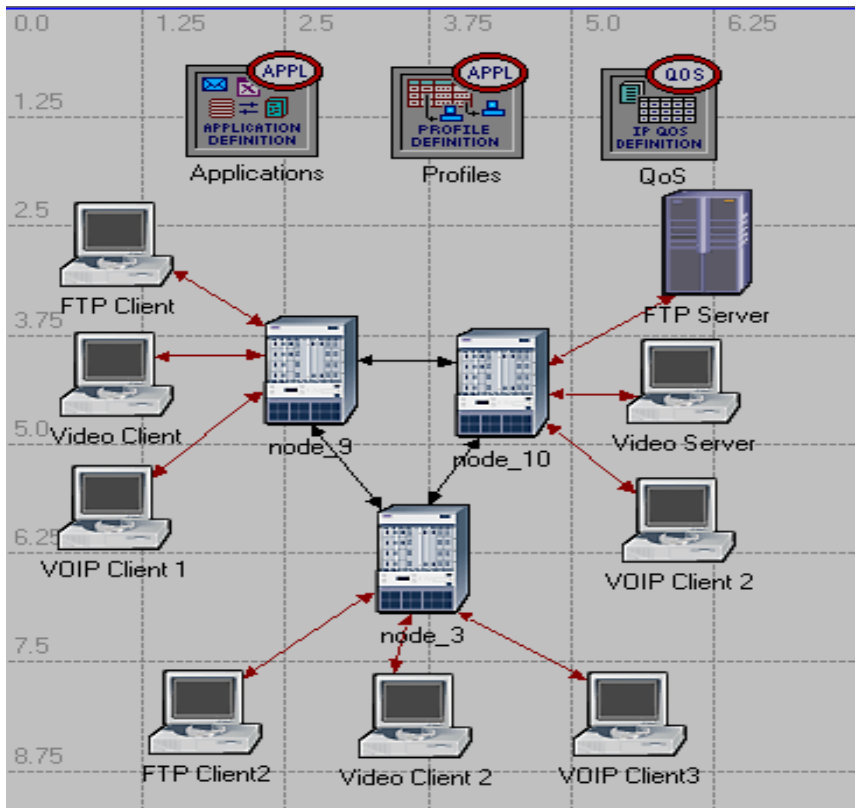

Figure 4. Network architecture for FIFO, PQ and WFQ for Intermediate load 


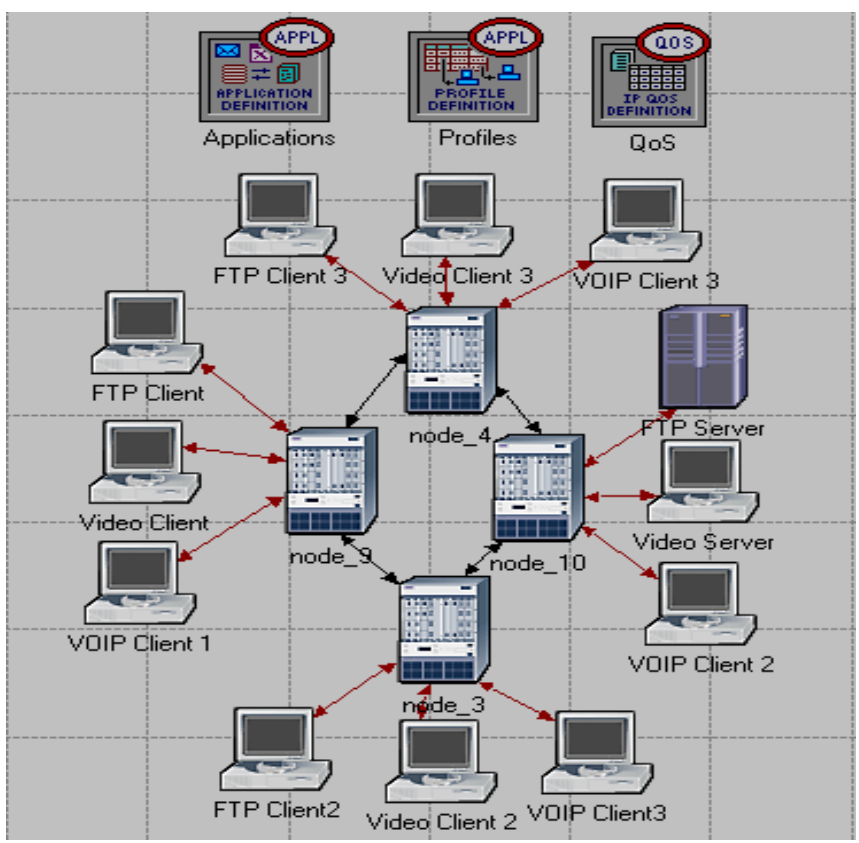

Figure 5. Network architecture for FIFO, PQ and WFQ for heavy load

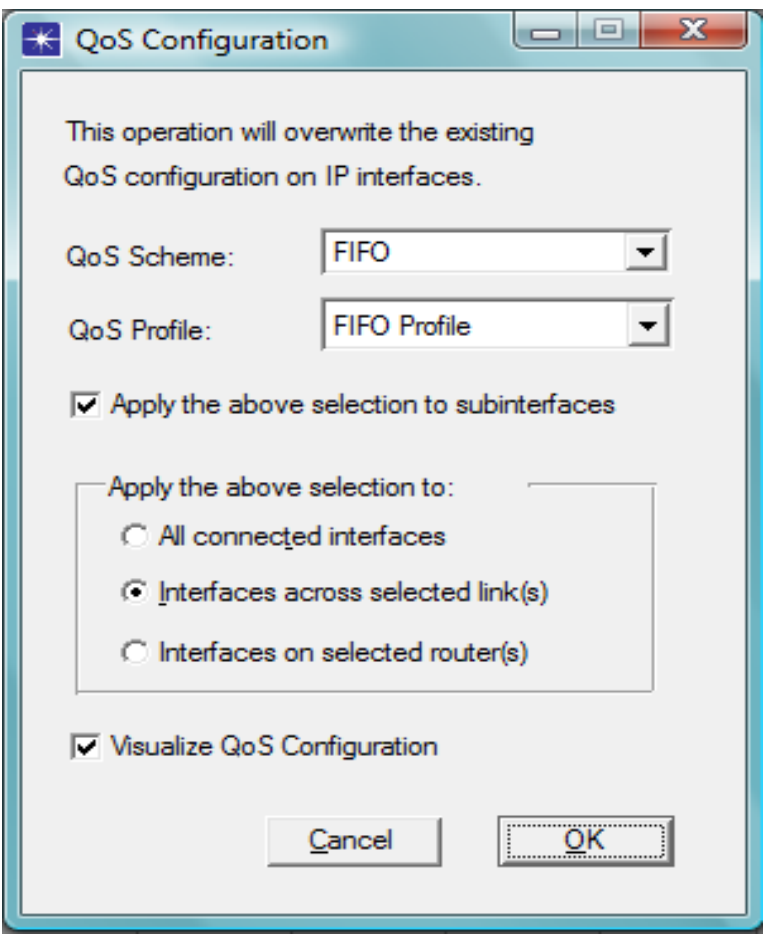

Figure 6. QoS Configuration
The architecture has been further modified and a bandwidth of $50 \mathrm{Mbps}$ to $100 \mathrm{Mbps}$ has been considered for $3 \mathrm{G}$ network and tested multimedia content delivery over this network.

For $4 \mathrm{G}$ networks the architecture has been modified and considered bandwidth up to $1 \mathrm{Gbps}$ and tested for multimedia content delivery over this network. Packet end to end delay and packet delay variation has been evaluated for all the network configuration model using different queuing discipline.

Different queuing discipline in the routers can affect the performance of the applications and the utilization of the network resources. Routers need to be configured for those three Queuing disciplines. The configurations are given Fig.6

\section{SIMULATIONS RESULTS AND ANALYSIS}

Simulation has been done using OPNET software for every queuing scheme and packet end to end delay, packet delay variation and traffic dropped is measured for variable bandwidth. It is tested for voice traffic and video conferencing.

Table 1, 2, 3 shows packet end to end delay and packet delay variation for FIFO, PQ and WFQ scheme for audio and video over variable bandwidth. These results have been evaluated for light load condition network configuration model. It has been also observed that results are similar for intermediated load and heavy load network configuration model for $100 \mathrm{Mbps}$ and $1 \mathrm{Gbps}$.

Fig 7, 8 and 9 shows packet end to end delay in case of voice transmission for light load, intermediate load and heavy load configuration model. Packet end to end time delay is nearly zero for both PQ and WFQ scheme. As the time increases PQ and WFQ groups packet shows same characteristic. Packet end to end delay is always higher in case of FIFO scheme.

TABLE 1. STATISTICS OF FIFO SCHEME OVER VARIABLE BANDWIDTH

\begin{tabular}{|c|c|c|c|c|}
\hline Bandwidth & \multicolumn{2}{|c|}{ FIFO (Audio) } & \multicolumn{2}{c|}{ FIFO (Video) } \\
\cline { 2 - 5 } & $\begin{array}{c}\text { Packet } \\
\text { End To } \\
\text { End Delay } \\
\text { (Sec) }\end{array}$ & $\begin{array}{c}\text { Packet } \\
\text { Delay } \\
\text { Variation } \\
\text { (Sec) }\end{array}$ & $\begin{array}{c}\text { Packet } \\
\text { End To } \\
\text { End Delay } \\
\text { (Sec) }\end{array}$ & $\begin{array}{c}\text { Packet } \\
\text { Delay } \\
\text { Variation } \\
\text { (Sec) }\end{array}$ \\
\hline $10 \mathrm{Mbps}$ & 0.9208 & 0.0684 & 0.845 & 0.056 \\
\hline $100 \mathrm{Mbps}$ & 0.915479 & 0.0693365 & 0.864995 & 0.057727 \\
\hline $1 \mathrm{Gbps}$ & 0.794608 & 0.057637 & 0.748554 & 0.0432041 \\
\hline
\end{tabular}


TABLE 2. STATISTICS OF PQ SCHEME OVER VARIABLE BANDWIDTH

\begin{tabular}{|c|c|c|c|c|}
\hline Bandwidth & \multicolumn{2}{|c|}{ PQ (Voice) } & \multicolumn{2}{c|}{ PQ (Video) } \\
\cline { 2 - 5 } & $\begin{array}{c}\text { Packet } \\
\text { End To } \\
\text { End Delay } \\
\text { (Sec) }\end{array}$ & $\begin{array}{c}\text { Packet } \\
\text { Delay } \\
\text { Variation } \\
\text { (Sec) }\end{array}$ & $\begin{array}{c}\text { Packet End } \\
\text { To End } \\
\text { Delay (Sec) }\end{array}$ & $\begin{array}{c}\text { Packet } \\
\text { Delay } \\
\text { Variation } \\
\text { (Sec) }\end{array}$ \\
\hline $10 \mathrm{Mbps}$ & 0.364336 & 0.00728955 & 0.00428886 & $\begin{array}{c}0.00000506 \\
62\end{array}$ \\
\hline $100 \mathrm{Mbps}$ & 0.338956 & 0.00623114 & 0.00414799 & $\begin{array}{c}0.00000510 \\
6\end{array}$ \\
\hline $1 \mathrm{Gbps}$ & 0.32047 & 0.00529942 & 0.00412595 & $\begin{array}{c}0.00000508 \\
61\end{array}$ \\
\hline
\end{tabular}

TABLE 3. STATISTICS OF PQ SCHEME OVER VARIABLE BANDWIDTH

\begin{tabular}{|c|c|c|c|c|}
\hline \multirow{2}{*}{ Bandwidth } & \multicolumn{2}{|c|}{ WFQ (Voice) } & \multicolumn{2}{c|}{ WFQ (Video) } \\
\cline { 2 - 5 } & $\begin{array}{c}\text { Packet End } \\
\text { To End } \\
\text { Delay (Sec) }\end{array}$ & $\begin{array}{c}\text { Packet } \\
\text { Delay } \\
\text { Variation } \\
\text { (Sec) }\end{array}$ & $\begin{array}{c}\text { Packet } \\
\text { End To } \\
\text { End } \\
\text { Delay } \\
\text { (Sec) }\end{array}$ & $\begin{array}{c}\text { Packet } \\
\text { Delay } \\
\text { Variation } \\
\text { (Sec) }\end{array}$ \\
\hline $10 \mathrm{Mbps}$ & 0.0042 & $\begin{array}{c}0.000005026 \\
5\end{array}$ & 3.83405 & 1.50679 \\
\hline $100 \mathrm{Mbps}$ & 0.00416661 & $\begin{array}{c}0.000005006 \\
6\end{array}$ & 3.97437 & 1.50678 \\
\hline $1 \mathrm{Gbps}$ & 0.00413858 & $\begin{array}{c}0.000005026 \\
5\end{array}$ & 2.08074 & 0.524183 \\
\hline
\end{tabular}

Fig 10, 11 and 12 shows packet delay variation in case of voice transmission for light load, intermediate load and heavy load configuration model. Packet delay variation is nearly zero for both PQ and WFQ scheme. As the time increases PQ and WFQ groups packet shows same characteristic. Packet delay variation is always higher in case of FIFO scheme.

Fig. 13, 14 and 15 shows packet end to end delay for video transmission for light load, intermediate load and heavy load configuration model. Here packet end to end time delay is higher for WFQ scheme where as it is lower for PQ scheme. Packet end to end delay is always higher in case of FIFO scheme.

Fig 16, 17 and 18 shows packet delay variation in case of video transmission for light load, intermediate load and heavy load configuration model. Here packet delay variation is higher for WFQ scheme where as it is lower for PQ scheme. Packet delay variation is always higher in case of FIFO scheme.
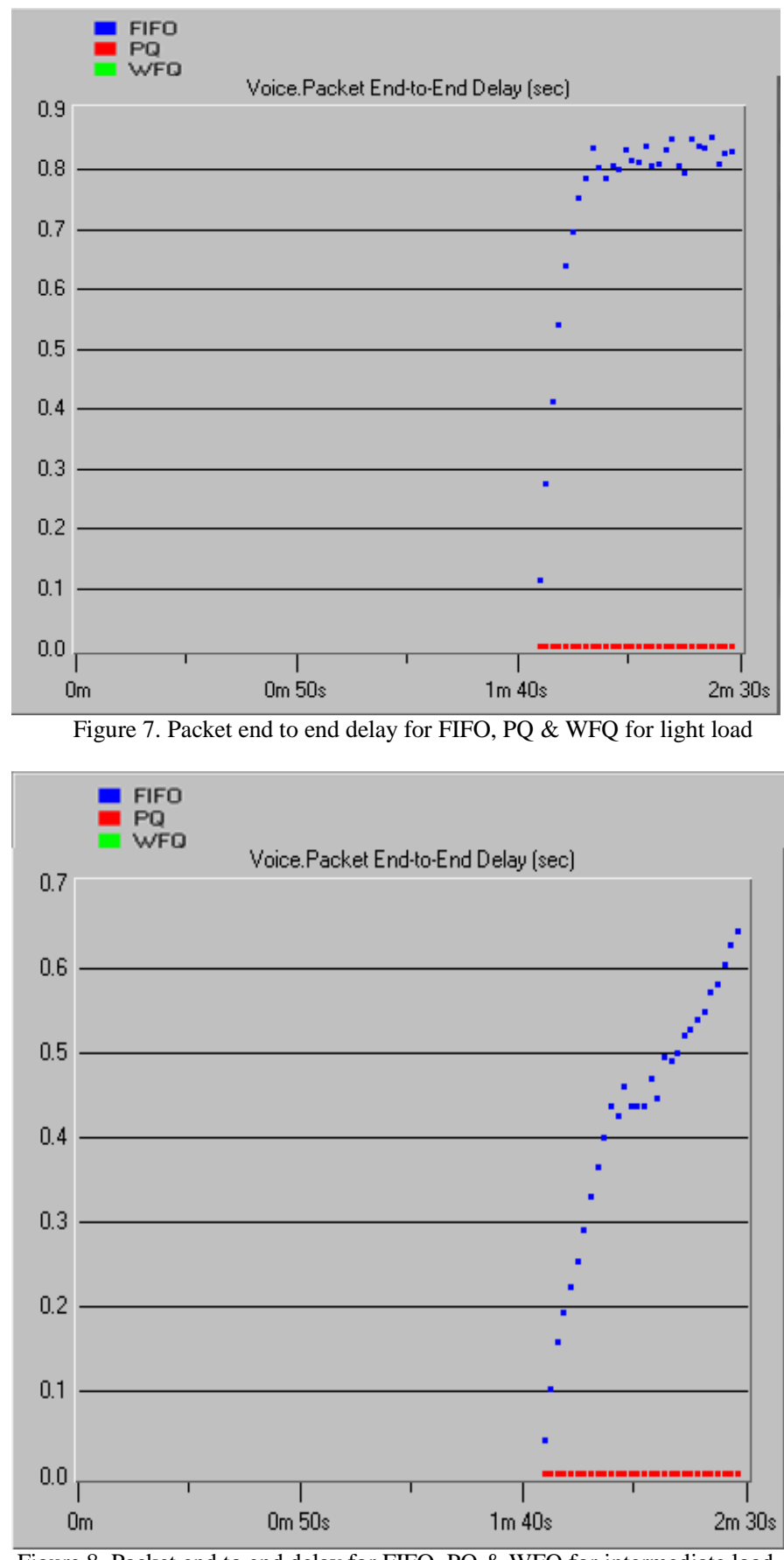

Figure 8. Packet end to end delay for FIFO, PQ \& WFQ for intermediate load 


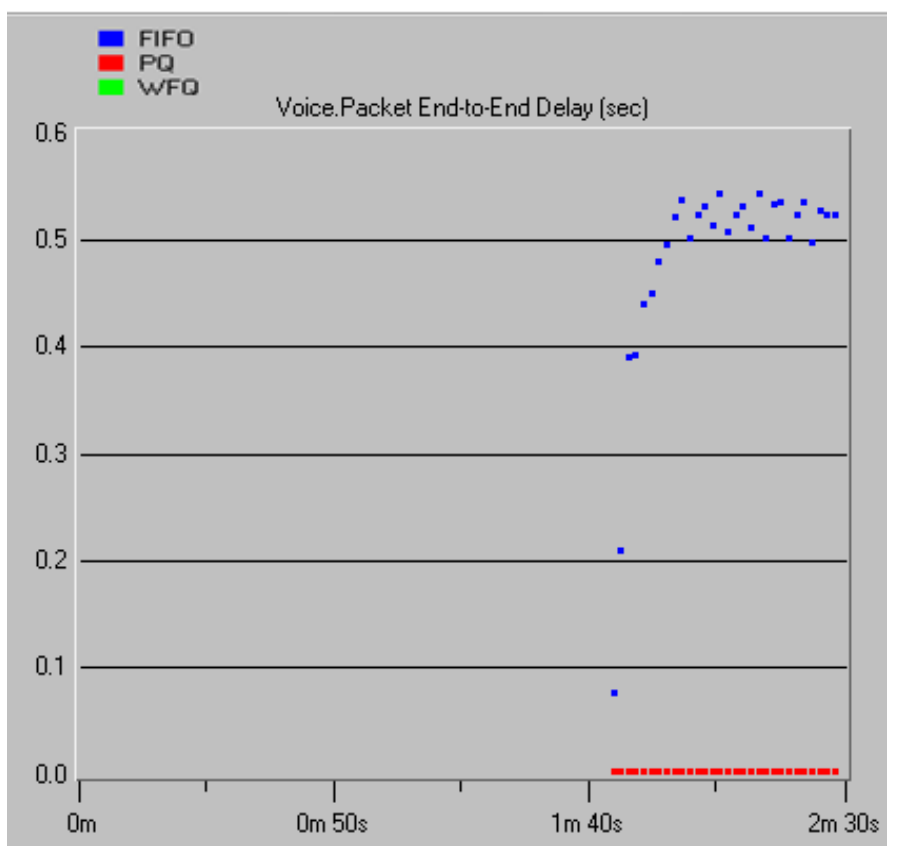

Figure 9. Packet end to end delay for FIFO, PQ \& WFQ for heavy load

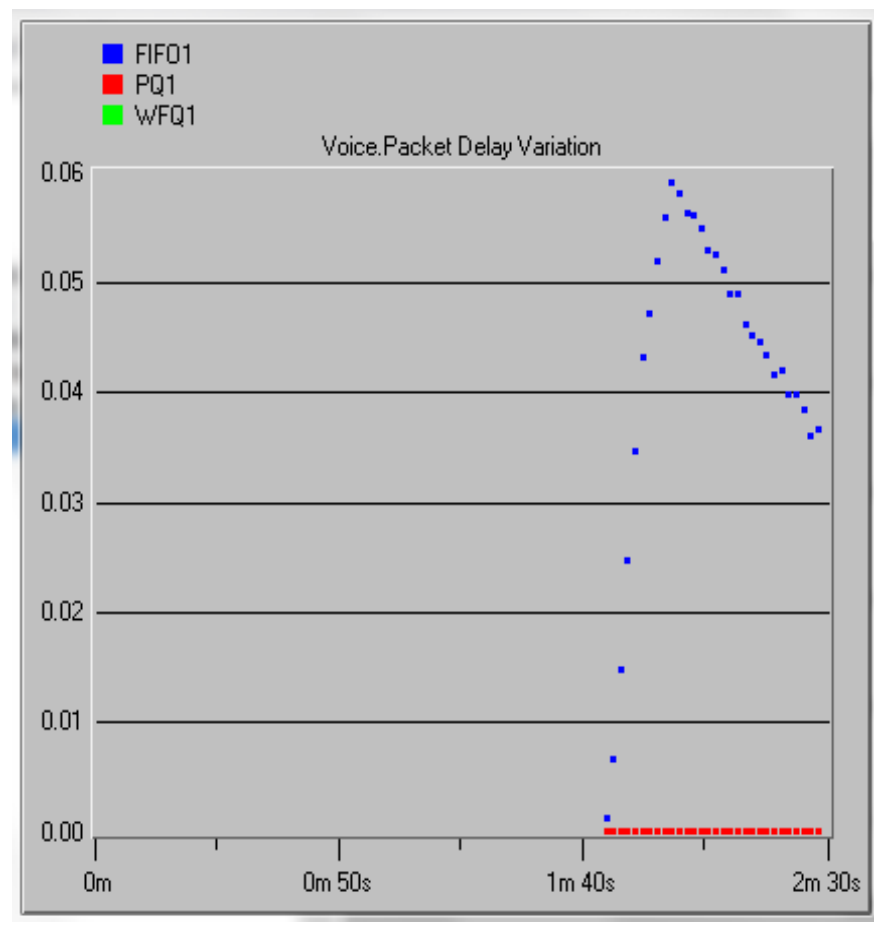

Figure 10. Packet Delay Variation for FIFO, PQ \& WFQ for light load

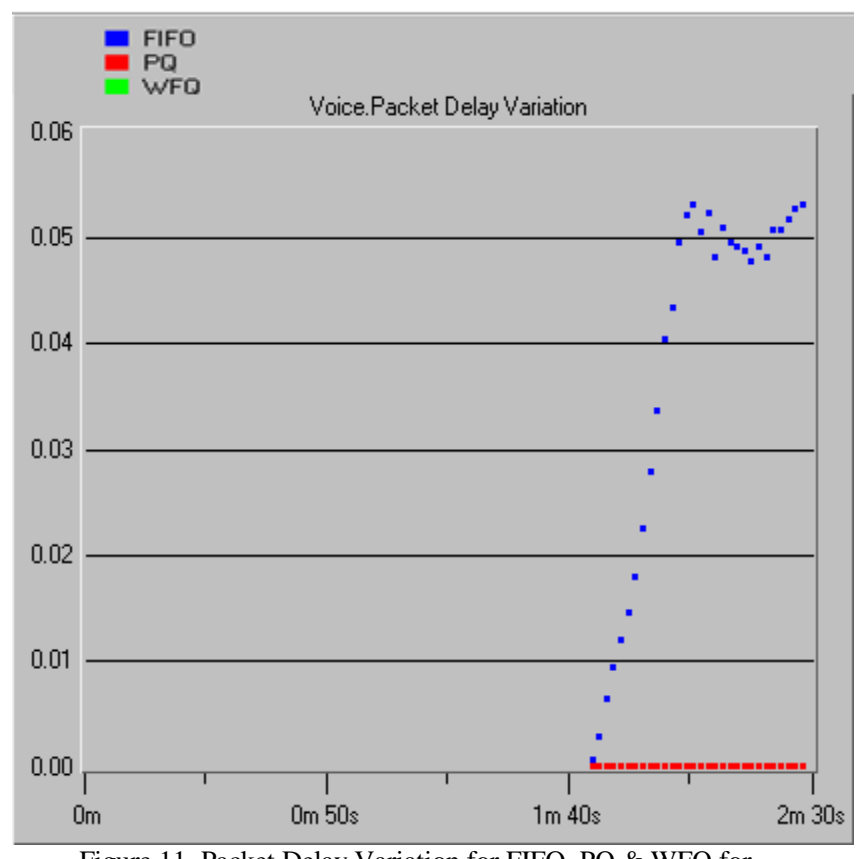

Figure 11. Packet Delay Variation for FIFO, PQ \& WFQ for intermediate load

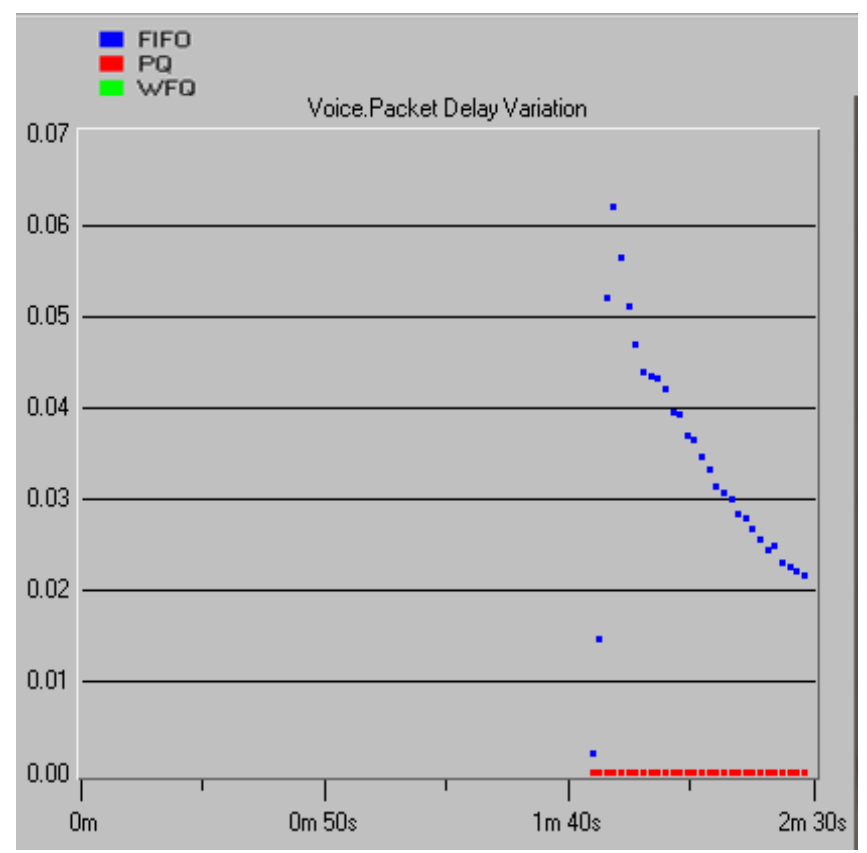

Figure 12. Packet Delay Variation for FIFO, PQ \& WFQ for heavy load. 
Table 4. Statistics of Packet End to End Delay for voice application

\begin{tabular}{|c|c|c|c|}
\hline \multirow{2}{*}{$\begin{array}{c}\text { Network } \\
\text { Configuration }\end{array}$} & \multicolumn{3}{|c|}{ Packet End To End delay (Sec) } \\
FIFO & PQ & WFQ \\
\hline Light load & 0.853373 & 0.00427152 & 0.00427152 \\
\hline Intermediate load & 0.643753 & 0.00300662 & 0.00300662 \\
\hline Heavy load & 0.543209 & 0.00281125 & 0.00275496 \\
\hline
\end{tabular}

Table 5. Statistics of Packet Delay Variation for voice application

\begin{tabular}{|c|c|c|c|}
\hline \multirow{2}{*}{$\begin{array}{c}\text { Network } \\
\text { Configuration }\end{array}$} & \multicolumn{3}{|c|}{ Packet Delay Variation (Sec) } \\
FIFO & PQ & WFQ \\
\hline Light load & 0.36158940 & 0.000005086 & 0.000005026 \\
\hline $\begin{array}{c}\text { Intermediate } \\
\text { load }\end{array}$ & 0.05344370 & 0.00000331 & 0.000005132 \\
\hline Heavy load & 0.02201986 & 0.00000373 & 0.000003874 \\
\hline
\end{tabular}

Table 4 and Table 5 shows packet end to end delay and packet delay variation for FIFO, PQ and WFQ scheme for voice applications.

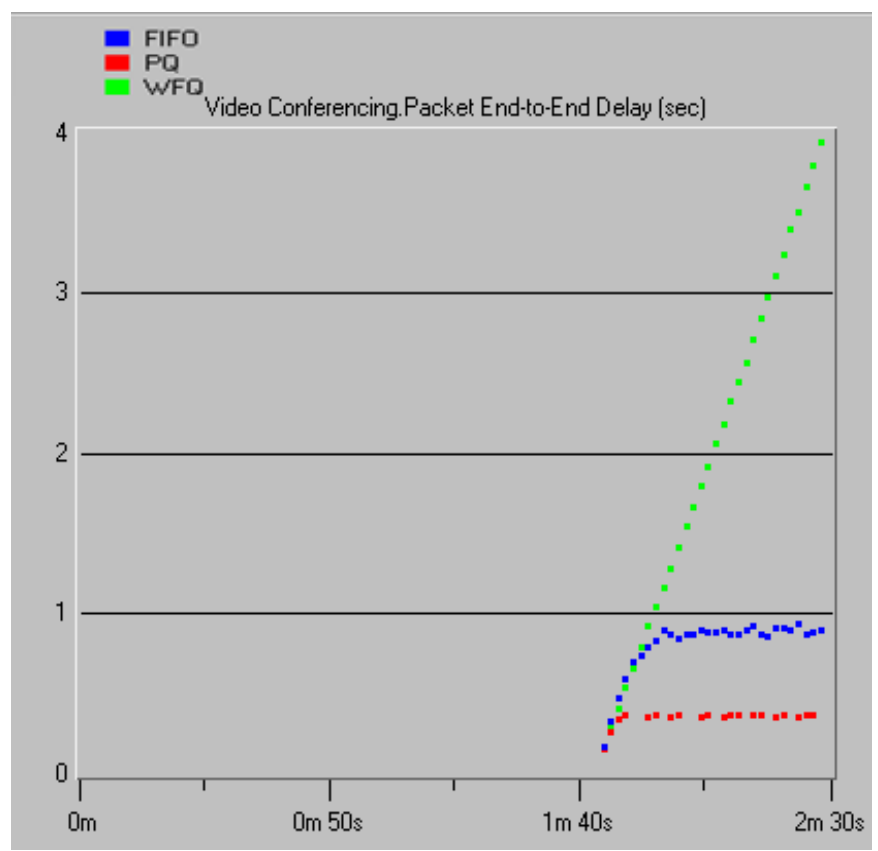

Figure 13. Packet end to end delay for FIFO, PQ \& WFQ for light load

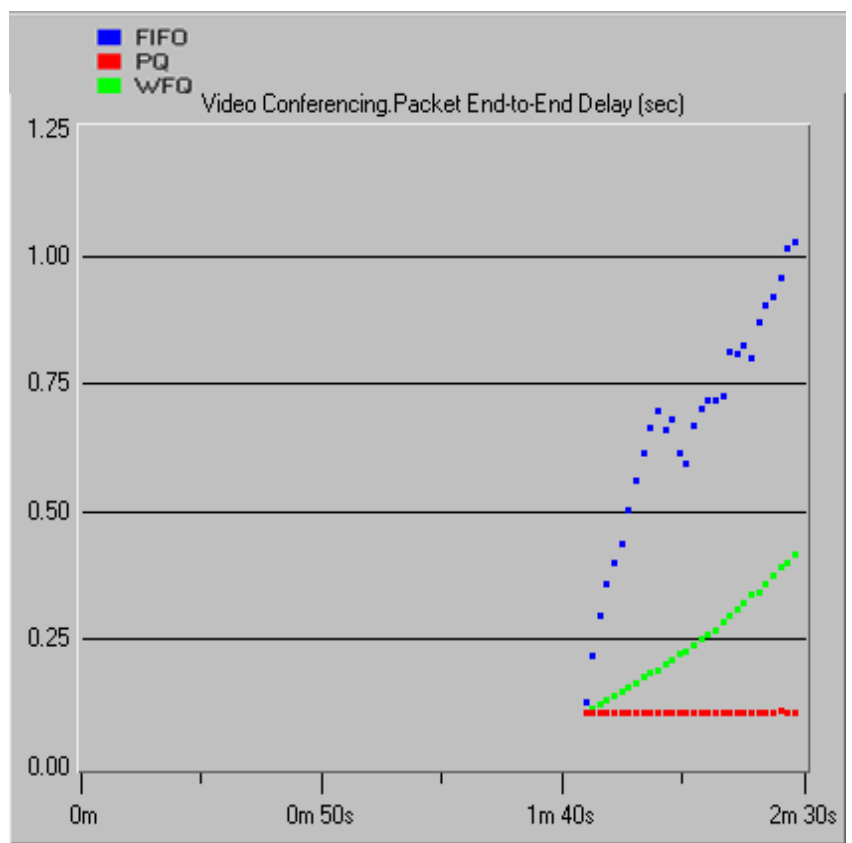

Figure 14. Packet end to end delay for FIFO, PQ \& WFQ for intermediate load

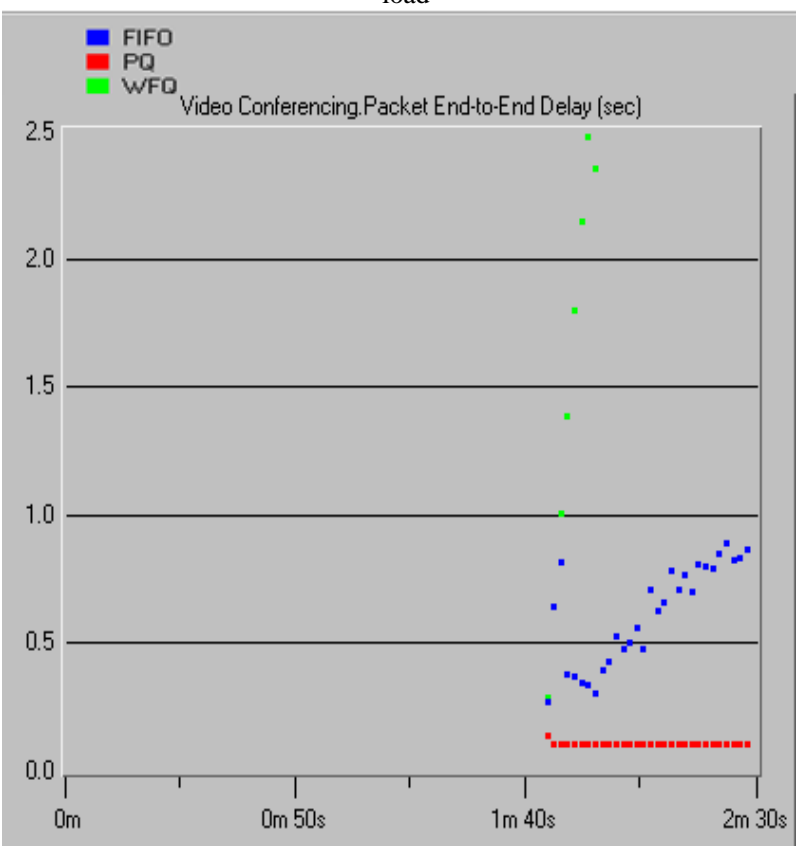

Figure 15. Packet end to end delay for FIFO, PQ \& WFQ for heavy load. 


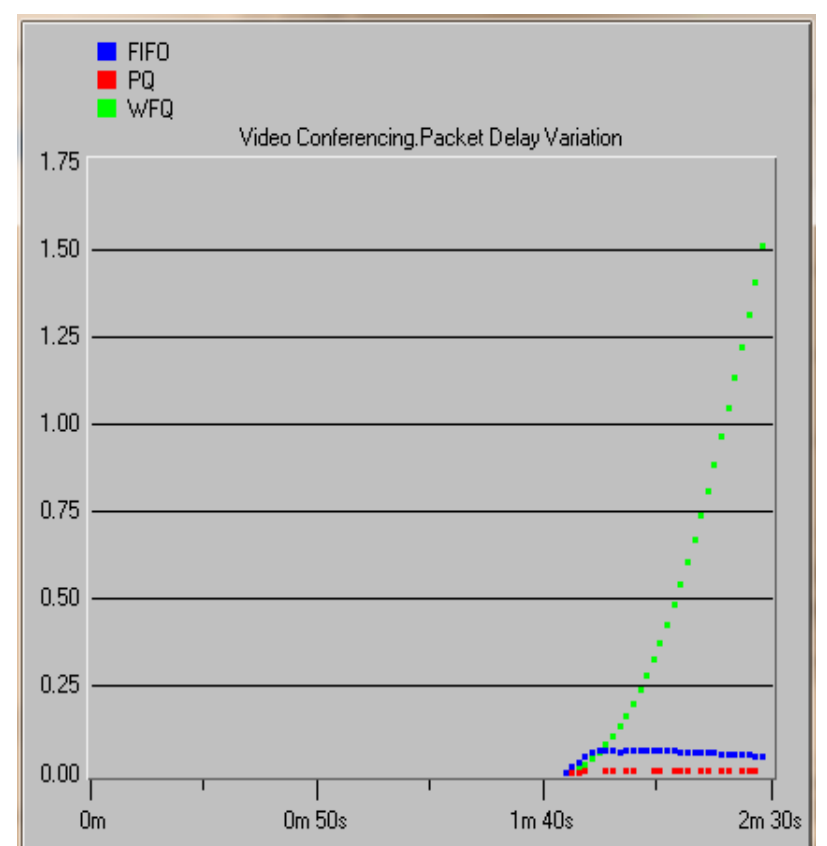

Figure 16. Packet Delay Variation for FIFO, PQ \& WFQ for light load

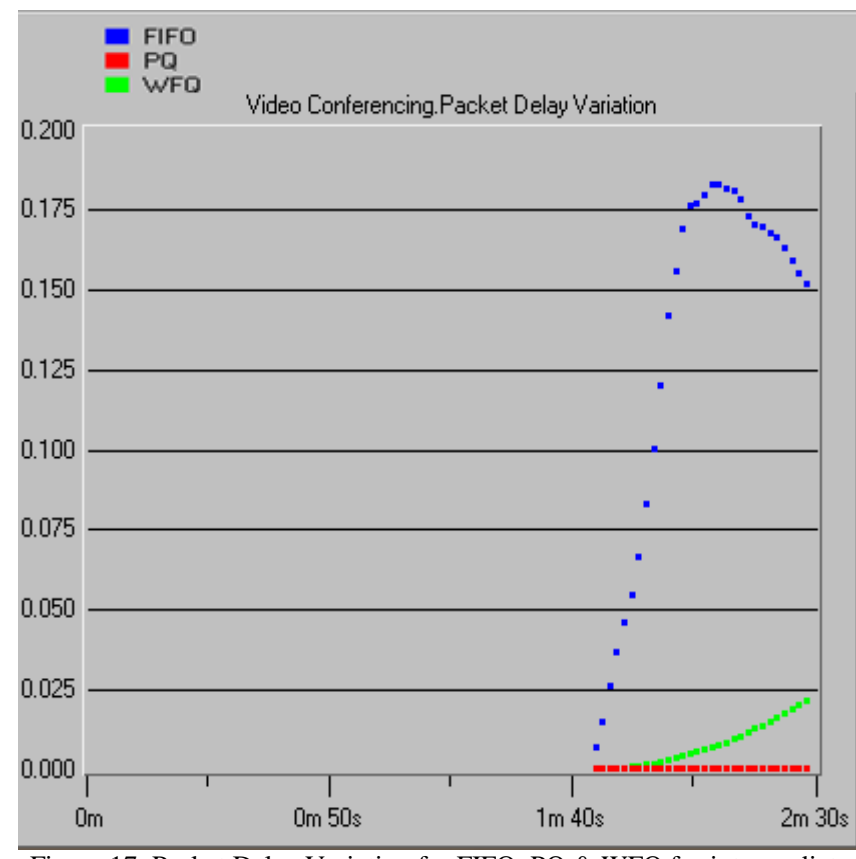

Figure 17. Packet Delay Variation for FIFO, PQ \& WFQ for intermediate load.

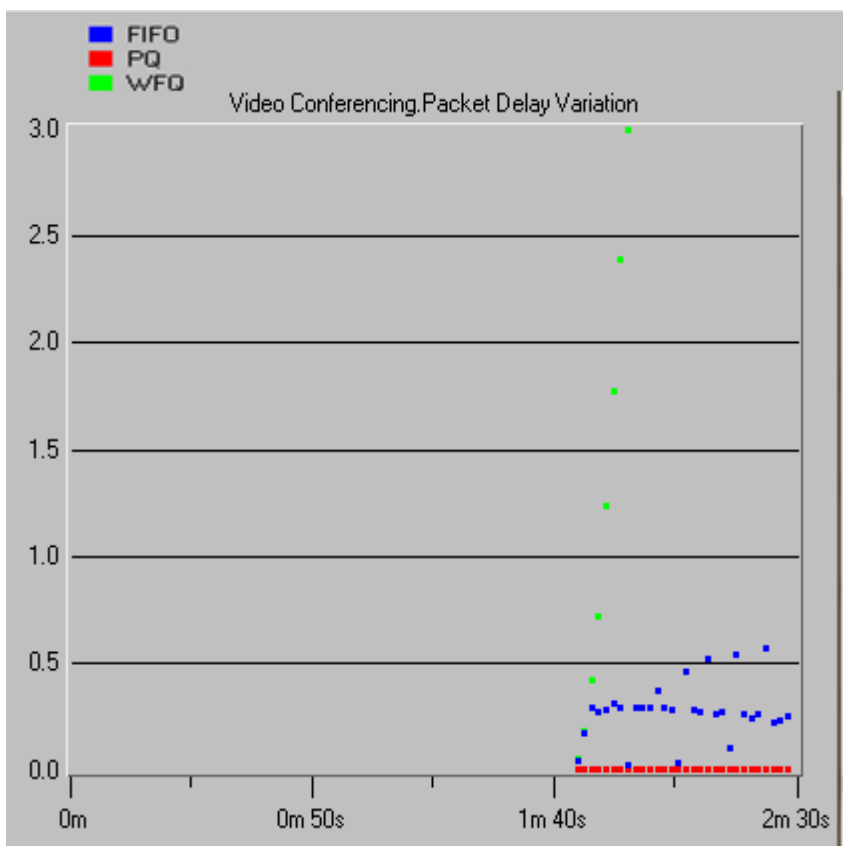

Figure 18. Packet Delay Variation for FIFO, PQ \& WFQ for heavy load.

Table 6. Statistics of Packet End to End Delay for video application

\begin{tabular}{|c|c|c|c|}
\hline $\begin{array}{c}\text { Network } \\
\text { Configuration }\end{array}$ & \multicolumn{3}{|c|}{ Packet End To End delay (Sec) } \\
FIFO & PQ & WFQ \\
\hline Light load & 0.92777 & 0.364327 & 3.93516 \\
\hline $\begin{array}{c}\text { Intermediate } \\
\text { load }\end{array}$ & 1.02772 & 0.106788079 & 0.417723 \\
\hline Heavy load & 0.890911 & 0.105298013 & 0.11589403 \\
\hline
\end{tabular}

Table 7. Statistics of Packet Delay Variation for video application

\begin{tabular}{|c|c|c|c|}
\hline $\begin{array}{c}\text { Network } \\
\text { Configuration }\end{array}$ & \multicolumn{3}{|c|}{ Packet Delay Variation (Sec) } \\
PQ & WFQ \\
\hline Light load & 0.054039735 & 0.007205298 & 1.50697 \\
\hline $\begin{array}{c}\text { Intermediate } \\
\text { load }\end{array}$ & 0.15231788 & 0.0000063576 & 0.0214625 \\
\hline Heavy load & 0.569669 & 0.0000463576 & 0.01986754 \\
\hline
\end{tabular}

Table 6 and Table 7 shows packet end to end delay and packet delay variation for FIFO, PQ and WFQ scheme for video applications.

It is observed that, both packet end to end delay and packet delay variation are higher in all the cases for FIFO. On other side, PQ and WFQ gives the same results when implemented in the above configuration model. The packet end to end delay and packet delay variation comes out to be $4 \mathrm{~ms}$ and $0.005 \mathrm{~ms}$ which is less and are acceptable for voice applications. 


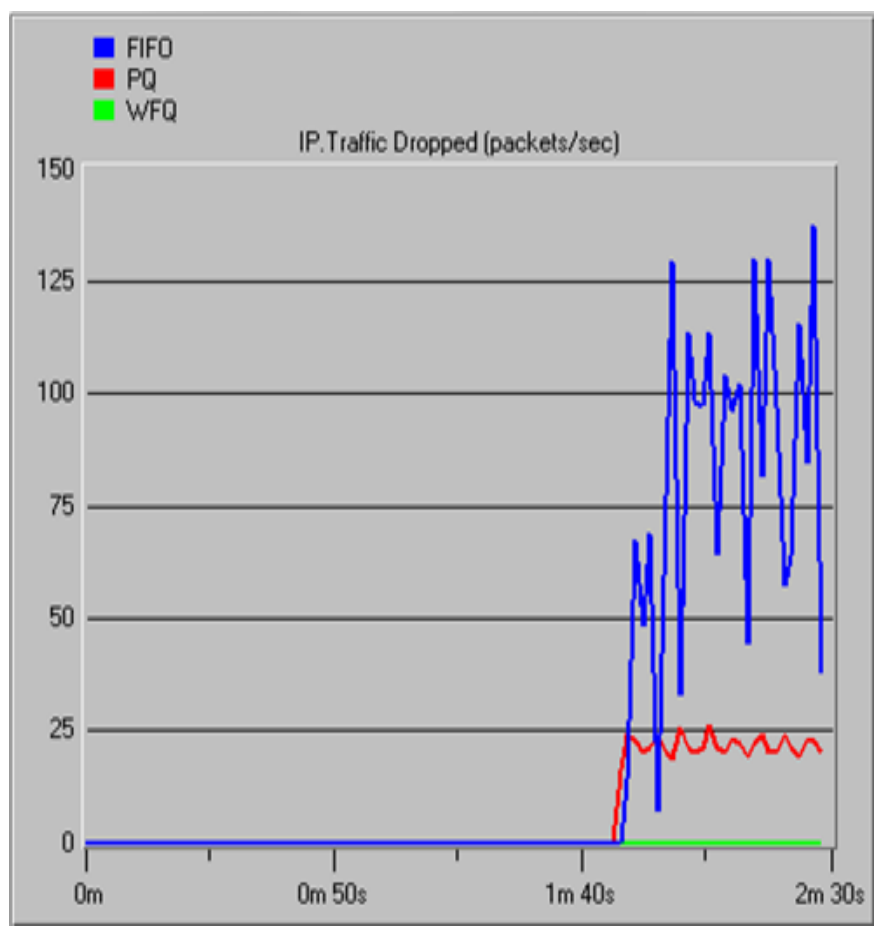

Figure 19. Traffic dropped for FIFO, PQ and WFQ for light load configuration.

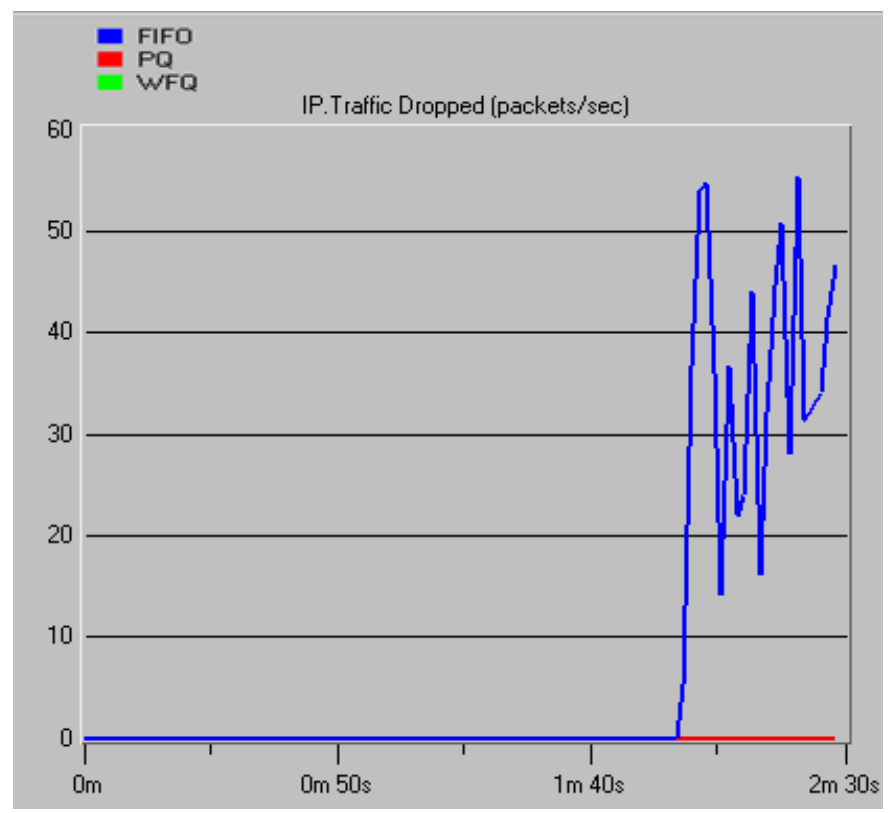

Figure 20. Traffic dropped for FIFO, PQ and WFQ for intermediate load configuration.

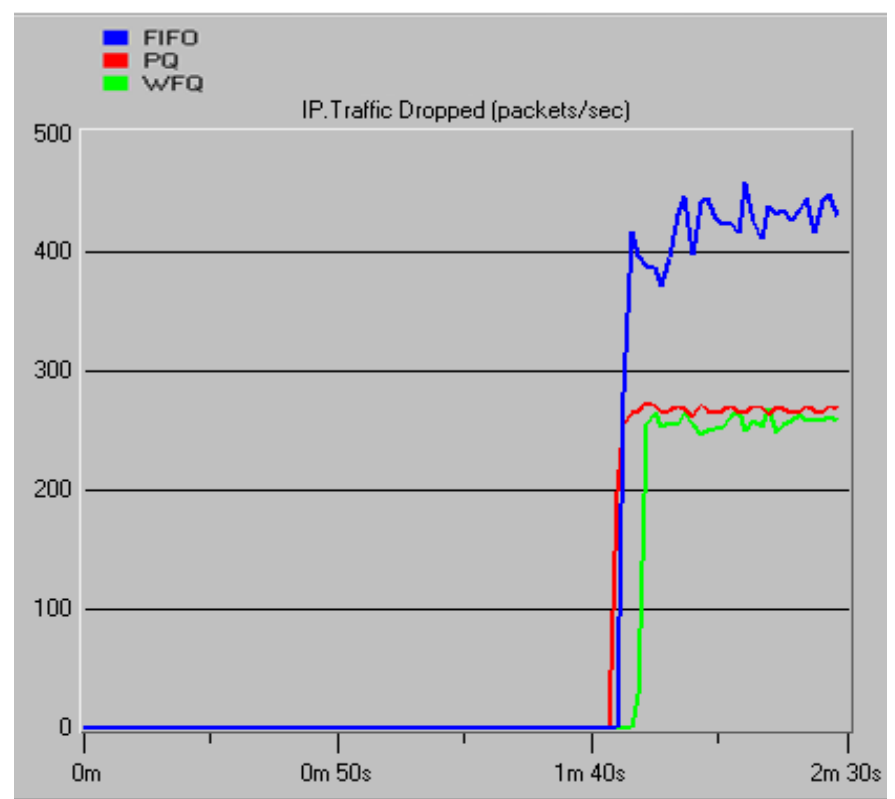

Figure 21. Traffic dropped for FIFO, PQ and WFQ for heavy load configuration.

Table 8. Statistics for IP Traffic Dropped

\begin{tabular}{|l|l|l|l|}
\hline \multirow{2}{*}{$\begin{array}{c}\text { Network } \\
\text { Configuration }\end{array}$} & \multicolumn{3}{|c|}{ No. of Packets Dropped } \\
\cline { 2 - 4 } & FIFO & PQ & WFQ \\
\hline Light load & 139 & 26 & 1 \\
\hline $\begin{array}{l}\text { Intermediate } \\
\text { load }\end{array}$ & 55 & 1 & 1 \\
\hline Heavy load & 458 & 273 & 267 \\
\hline
\end{tabular}

Fig 19, 20 shows traffic drop statistic. Fig 21 shows traffic drop statistic for heavy load condition and also Table V shows the statistical figures for the traffic dropped.

It has been observed that as the traffic drop is higher in FIFO scheme for all the network configuration model. For WFQ scheme it is minimum in all the network configuration model.

\section{CONCLUSION}

It has been observed after comparing the detail statistics of the result that packet end to end delay, packet delay variation and Traffic dropped is always higher in case of FIFO scheme for both voice and video based content deliver over network. Results have been evaluated for light load, intermediated load and heavy load configuration model.

PQ scheme gives better result in case of video based content delivery over the network. However WFQ gives best result among them. Result shows that traffic drop is almost zero in case of WFQ scheme. 
As per the presented result here in case of WFQ scheme packet end to end delay and packet delay variation are proper for audio based content but for video it is bit higher. Bandwidth of $10 \mathrm{Mbps}, 100 \mathrm{Mbps}$ and $1 \mathrm{Gbps}$ has been considered to do the critical analysis of above configuration model. Results are useful for performance modeling for $3 \mathrm{G}$ and $4 \mathrm{G}$ network.

\section{ACKNOWLEDGEMENT}

Our sincere thanks to Thakur educational trust and management to provide all the facilities and infrastructure to carried out the research work.

\section{REFERENCES}

[1] Pascal Lorenz, "QOS in Next Generation Network. 26th International Conference Interfaces ITI 2004, June 7-10.

[2] Neill Weilkinson "Next Generation Network Services Technologies and Strategies" john willey and sons ltd pp 167-170.

[3] ITU-T Recommendation G.114: One-way transmission time; 05/2000.

[4] B.R haverkort, R Marie, G Rubino and K.S Trivedi, “ Performability Modelling: Techniques and Tools, Wiley, New York,2001

[5] G Bolch,S.Greiner,H.De Meer "Modelling and Performance evaluation with computer science Applications. Wiley, New York 1998.

[6] Thomas G. Robertazzi "Computer Network and System. $3^{\text {rd }}$ edition, pages 20-85.

[7] Kumar, S.; Kumar, P.R.; Performance bounds for queueing networks and scheduling policies IEEE Transactions Volume 39, Issue 8, Aug. 1994 pp 1600 - 1611

[8] I Akyildiz, "Exact product form solution for queuing networs with blocking," IEEE Trans Comput.. 36(1), 122-25 1987.

[9] J.P Buzen "Computational algorithm for closed queuing networks with exponential servers" Commun. ACM [1973] pp 527-531

[10] P.J Burke,"output of a queuing system" page(s): 699-704. [11] "FIFO
http://www.daxnetworks.com/Technology/TechDost/TD-032206.pdf

[12] Taddia, C.; Mazzini, G.; On the Jitter Performance of FIFO and Priority Queues Mixture IEEE 17th International Symposium on 2006, Page(s): $1-5$

[13] Balogh, T.; Medvecky, M.; "Performance evaluation of WFQ, WF2Q+ and WRR queue scheduling algorithms ",Telecommunications and
Signal Processing (TSP), 2011 34th International Conference 2011 , Page(s): 136 - 140

[14] Network World, "Weighted Fair Queuing" http://www.networkworld.com/details/659.html

[15] Mong-Fong Homg; Wei-Tsong Lee; Kuan-Rong Lee; Yau-Hwang Kuo; An adaptive approach to weighted fair queue with QoS enhanced on IP network Proceedings of IEEE Region 10 International Conference on Volume: 12001 , Page(s): $181-186$

[16] Mohammad Mirza Golam Rashed and Mamun Kabir" a comparative study of different queuing techniques in voip, video conferencing and file transfer" daffodil international university journal of science and technology, volume 5, issue 1, January 2010 pp 37-47.

[17] Mong-Fong Homg; Wei-Tsong Lee; Kuan-Rong Lee; Yau-Hwang Kuo; An adaptive approach to weighted fair queue with QoS enhanced on IP network Proceedings of IEEE Region 10 International Conference on Volume: 12001 , Page(s): $181-186$

\section{Authors Profile}

Dr.B.K.Mishra was born in the year 1966 and has completed his Bachelor of Engineering in Electronics from Amravati University in the year 1988, M.E. in Electronics and Communication Engineering in the year 1992 and Ph. D Engineering in Electronics \& Communication Engineering in 1998 from Birla Institute of Technology, Ranchi. He is having a teaching experience of more than 18 years with research experience of 4 years. He has published more than 20 technical papers in the National and International Journals including the proceedings of National and International conferences. He has also published six text books in the area of Electronics Devices and Circuits and Communication. The area of interest includes the Communication Engineering and Electronic Circuits. Currently he is working as a Principal of Thakur College of Engineering \& Technology since $12^{\text {th }}$ June' 06 .

S.K Singh is Head of Information technology department of Thakur College of Science and Commerce affiliated to University of Mumbai. He has received his M.E degree in Information Technology in 2006. He is having a teaching experience of more than 10 years at UG and PG level and currently he is research scholar in NMIMS University-Mumbai and his research interest include quality of service, next generation network and Packet inspection. He has published more than 10 technical papers in the National and International Journals including the proceedings of National and International conferences.

Ruchi Shah is Post Graduate Student in Thakur College of Science and Commerce affiliated to University of Mumbai. Her research interest include Networks, Mobile Communication, Next Generation Network and Distributed Computing. 